dermatoses with simple mixtures of inorganic salts and allantoin derivatives. ${ }^{19}$

These diverse topical preparations possess the merits of both cheapness and freedom from the disadvantages of most antibiotics. Well-designed comparative clinical trials, particularly of the antiseptic paints and other traditional preparations, are long overdue.

1 Noble, W C, and Naidoo, J, British fournal of Dermatology, 1978, 98, 481.

2 Porthouse, A, et al, Lancet, 1976, 1, 20.

3 Ayliffe, G A J, et al, fournal of Clinical Pathology, 1977, 30, 40.

${ }^{4}$ Lacey, R W, Fournal of Medical Microbiology, 1971, 4, 73.

5 Selwyn, S, and Chalmers, D, British fournal of Dermatology, 1965, 77, 349.

6 British Medical fournal, 1978, 1, 1573.

7 British Medical fournal, 1977, 1, 1494.

${ }^{8}$ British Medical fournal, 1977, 1, 337.

9 Tuke, W, Nursing Times, 1975, 71, 21

10 George, R H, in Chemotherapy, vol 3, eds J D Williams and A M Geddes, p 3. New York, Plenum Publishing Company, 1976.

11 Shepherd, R C, and Kinmonth, J B, British Medical fournal, 1962, 2, 151.

12 Grant, J C, British Medical fournal, 1968, 4, 646.

13 Lowbury, E J L, et al, British Medical fournal, 1976, 1, 493.

14 Babb, J R, et al, Burns, 1977, 3, 65.

15 Gilmore, O J A, Annals of the Royal College of Surgeons of England, 1977, $59,93$.

${ }^{16}$ Georgiade, N G, and Harris, W A, Plastic and Reconstructive Surgery, 1973, 52, 640 .

17 Pollock, A V, and Evans, M, British fournal of Surgery, 1975, 62, 292.

18 Carpenter, C L, et al, Current Therapeutic Research, 1973, 15, 650.

19 Copeman, P W M, and Selwyn, S, British Medical fournal, 1975, 4, 264.

\section{HLA-B27 and risk of ankylosing spondylitis}

About three-quarters of a million people in Britain $(1.6 \%$ of the population) have or will develop ankylosing spondylitis. Previously the disease was thought to occur in about $0.2 \%$ of men and in only $0.03 \%$ of women. ${ }^{1-3}$ Now it is found to affect men and women with equal frequency. This radical revision has been made possible by the discovery of a strong association $^{4} 5$ between ankylosing spondylitis and the gene for the transplantation antigen B27, since this led to better case finding. Studies in the United States on 78 apparently healthy men and women blood donors carrying HLA-B27 showed that 16 had active pain and radiological signs consistent with ankylosing spondylitis. ${ }^{6}$ This was thought to be an underestimate because of the study's reliance on questionnaires and on $x$-ray films obtained before the study. A total of 126 B27negative controls, matched for race, sex, and age, did not include a single case. Similar results have been obtained by others. ${ }^{7}$ Since about $8 \%$ of whites are B27-positive, $1.6 \%$ of the population are likely to acquire ankylosing spondylitis. But for various reasons, in population studies the disease has been underdiagnosed by a factor of 10 in men and 80 in women. ${ }^{6}$

The low prevalence rate found in the "classical" population studies is hard to reconcile with the much higher rates found in these recent surveys of B27-positive individuals. But the proportion of first-degree relatives found to be affected is also much greater than the incidence in the traditional general population studies-about 30 times greater for men and about 100 times greater for women. ${ }^{8}$ This is not so different from the rates found in the new studies. Is this simply evidence for multifactorial causation, ${ }^{8}$ or could it be a case of "Seek and ye shall find"?

Although both types of investigation appear to have used objective clinical and radiological criteria, there does seem to have been a tendency to underdiagnose in the past. Ankylosing spondylitis frequently produces annoying pain but seldom dramatic symptoms. Physicians tend to neglect back pain and radiologists may be reluctant to diagnose sacroiliitis. The $\vec{z}$ belief that the disease is rare in women tends to be self- $\frac{\mathbb{Q}}{2}$ fulfilling and back pain in young women is often attributed to dysfunction of pelvic organs; and doctors are also laudably $\overrightarrow{\vec{S}}$ reluctant to radiograph the pelvis of women of reproductive $\overrightarrow{0}$ age. Moreover, men may be more likely to seek help since the type of work that they traditionally undertake will be limited $\frac{\bar{\sigma}}{\vec{D}}$

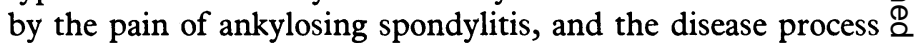
itself may be exacerbated by excessive muscular effort.

The association with B27 has also improved our knowledge $\overrightarrow{0}$ of the genetics of ankylosing spondylitis though the cause is still not clear. Since B27-negative people occasionally have the disease, ${ }^{9}$ the B27 gene itself is not essential. More probably $\frac{}{7}$ there is a gene conferring susceptibility to it on chromosome C6, separate from B27 but closely linked and usually inherited together with it. A single major gene, however, could not $\vec{\omega}$ account for all the facts. There is now considerable evidence ${ }^{10} \infty$ that ankylosing spondylitis, Reiter's syndrome, acute anterior (f uveitis, chronic inflammatory bowel disease, psoriasis, and $\frac{9}{7}$ acute infections of the bowel have related causes, suggesting $N$ multiple genes and environmental agents. B27, or a suscepti- $\mathbb{D}$ bility gene closely linked to it, is probably best regarded as just $\frac{\mathbb{Q}}{\vec{D}}$ one of a complex of factors.

What does all this mean in practice and when should HLA $\stackrel{\mathbb{D}}{-}$ typing be carried out? Although $20 \%$ or more of all B27- $\overrightarrow{0}$ positive people eventually develop ankylosing spondylitis, we should resist the temptation to screen for B27 in patients with unexplained backache as this would be costly and few results would be positive-the frequency of B27 in patients attending orthopaedic clinics with non-specific backache is almost the same as in the population at large. ${ }^{6}$ But when a $\stackrel{\mathscr{D}}{\mathscr{D}}$ patient has persistent backache, radiological signs, bowel $\underset{\vec{F}}{\overrightarrow{7}}$ disease, or other associated diseases, knowing whether he is $\frac{0}{3}$ B27-positive will help in making a diagnosis. HLA typing is, $\vec{F}$ however, most important in patients with chronic juvenile polyarthritis, who are likely to develop ankylosing spondylitis if they are B27-positive ${ }^{11}$ and can be saved much uncertainty and over-investigation by this relatively simple test.

What are the implications for clinical genetics? So far as white people but not necessarily other races are concerned, $\stackrel{\delta}{\beta}$ we can say the following. For the families of patients with ankylosing spondylitis genetic counselling now has some part $\stackrel{\circ}{工}$ to play and B27 typing may be helpful. As always, the doctor $N$ must get his facts right and be honest about the uncertainties. $\frac{D}{2}$ He should, for example, emphasise that people inheriting the gene or genes for ankylosing spondylitis do not necessarily $N$ develop the disease, and also that the severity varies widely; $N$ moreover, B27-negative relatives run little risk, and even for B27-positive relatives the precise risk is not yet clear. In white families about $7 \%$ of male first-degree relatives and $3 \%$ of $\Phi$ female first-degree relatives were found to develop ankylosing $\stackrel{+}{+}$ spondylitis. ${ }^{8}$ Consequently, as most affected relatives will be $\frac{0}{0}$ B27-positive, B27-positive first-degree male relatives should $\stackrel{\mathbb{Q}}{\stackrel{0}{*}}$ have about a $14 \%$ risk and B27-positive female relatives a $6 \% \frac{\overparen{Q}}{\mathbb{Q}}$ risk.

These rates differ, however, from those found in the studies ${ }^{6}{ }_{7}^{2}$ referred to earlier, in which at least $20 \%$ of B27 individuals, whether men or women, had ankylosing spondylitis. Indeed, the risk would be expected to be higher within families because of partially shared genes and environments. Thus families in which ankylosing spondylitis has occurred, it has been sug- 
gested, ${ }^{12}$ should be told that B27-positive individuals have a risk of between $20 \%$ and $40 \%$ of developing the disease but that many affected individuals will have slight or moderate symptoms. With regular physiotherapy and anti-inflammatory drugs most patients can go about satisfactorily and continue the usual routine of their lives. ${ }^{13}$ Those inheriting the B27 gene from both parents possibly run a greater risk, though without firmer evidence a geneticist could not reasonably advise prospective spouses to undergo premarital HLA typing. But eventually, perhaps, boys known to be B27-positive might select physically undemanding jobs that they would be able to keep if they developed ankylosing spondylitis.

There are no insurmountable technical obstacles to identifying B27-positive individuals at birth or even by prenatal diagnosis, but this could not be justified clinically. Most cases of ankylosing spondylitis are relatively mild, the onset is late, and there is no preventive treatment. Nevertheless, B27 is the most important known genetic marker of susceptibility to a disease and is undoubtedly the forerunner of many others that will identify constitutional susceptibilities. Identifying a cohort of B27-positive children for prospective study of the interaction of genes and environment in initiating disease would be of great epidemiological interest. We must not be over-sanguine, however, about the rewards of such an approach, since-as the continuing abuse of tobacco has shown - even unequivocal environmental triggers may be difficult to remove.

1 West, H F, Annals of the Rheumatic Diseases, 1949, 8, 143.

2 Lawrence, J S, British fournal of Clinical Practice, 1963, 17, 699.

${ }^{3}$ De Blécourt, J J, Polman, A, and De Blécourt-Meindersma, T, Annals of the Rheumatic Diseases, 1961, 20, 215.

${ }^{4}$ Brewerton, D A, et al, Lancet, 1973, 1, 904.

${ }^{5}$ Schlosstein, L, et al, New England fournal of Medicine, 1973, 288, 704.

${ }^{6}$ Calin, A, and Fries, J F, New England fournal of Medicine, 1975, 293, 835.

${ }^{7} \mathrm{Kidd}, \mathrm{K} \mathrm{K}$, et al, in HLA and Disease, eds J Dausset and A Svejgaard, p 72. Copenhagen, Munksgaard, 1977.

${ }^{8}$ Carter, C O, and Fairbank, T J, The Genetics of Locomotor Disorders, p 126. London, Oxford University Press, 1974.

${ }^{9}$ Dick, H M, et al, Lancet, 1974, 2, 24.

10 Brewerton, D A, Arthritis and Rheumatism, 1976, 19, 656.

${ }^{11}$ Edmonds, J, et al, Annals of the Rheumatic Diseases, 1974, 33, 289.

${ }^{12}$ Falace, P, et al, Clinical Genetics, 1978, 13, 380.

13 Calabro, J J, Clinical Orthopaedics, 1968, 60, 125.

\section{Rocky Mountain spotted fever}

Last year 1115 cases of Rocky Mountain spotted fever were reported in the United States, the highest number ever. The name suggests that the disease, an acute febrile illness caused by Rickettsia rickettsii and transmitted to man by ticks, is confined to western areas of the United States; but infection is widespread throughout the country and also occurs in Canada, Mexico, Panama, Colombia, and even Brazil. ${ }^{1}$ Of the four species of ticks that are natural hosts in the United States-Dermacentor andersoni, $D$ variabilis, Amblyomma americanum, and Haemaphysalis leporispalustris$D$ andersoni (the wood tick) and $D$ variabilis (the dog tick) are the most common cause of human infection. A wide variety of wild animals, including rabbits, hares, rodents, and ground squirrels, are natural reservoirs of infection. Domestic dogs act as amplifier hosts and increase the risk of human infection, especially in the eastern United States.

Before 1960 about 500 cases of Rocky Mountain spotted fever occurred annually in the United States and before the advent of broad-spectrum antibiotics $20 \%$ on average were fatal-a higher proportion in those aged over 40 . The use of chloramphenicol and tetracyclines dramatically reduced the death rate. Since 1960 there has been a steady increase in the number of reported cases. ${ }^{2}$ Of the 1115 cases reported in 1977, 42 were fatal, and over half the patients were under 20. The disease was particularly prevalent in southern and south-eastern States, North Carolina, Virginia, Tennessee, Maryland, and Oklahoma heading the list. The likely reasons for the increasing incidence are urban development in previously endemic areas and an increase in recreations that bring man into contact with the animal hosts. ${ }^{3}$

Man is usually infected by tick bite, but squashing ticks in attempts to remove them can cause infection through skin abrasions. The disease is primarily vascular, affecting small blood vessels in the skin, subcutaneous tissue, and central nervous system, but it may develop in any tissue or organ. ${ }^{4}$ Rickettsiae invade capillary endothelial nuclei, multiply, and destroy the cells, which causes blood to leak from the vessels. After an incubation period of 3-12 days the illness begins abruptly with severe headache, rigors, prostration, myalgia, and fever that continues, if untreated, for two to three weeks. The headache is usually excruciating. A characteristic enanthema appears about the fourth day, beginning on the extremities as discrete pink macules; this extends after 6-12 hours to the trunk, buttocks, face, and neck and becomes maculopapular and then petechial. The petechiae later coalesce to form a purpuric rash and ecchymoses. In severe cases delirium, shock, and renal failure follow, and the patient dies towards the end of the second week of illness. Mild and moderately severe infections, however, usually abate within two weeks and convalescence is rapid.

The main problem now is early diagnosis. Specific antibiotic treatment, which should be given when the enanthema appears or not later than the sixth day of illness, is generally followed by prompt and complete recovery. But if treatment is delayed intensive damage to blood vessels and tissues may have occurred. As the illness may be confused with measles, meningococcaemia, rubella, typhoid, glandular fever, and other rickettsial infections the diagnosis may not be made early enough. Isolating rickettsiae takes time and Weil-Felix agglutinins and complement-fixing antibodies do not rise until 10-14 days after the onset of illness. Woodward, ${ }^{5}$ however, recently indicated a means of rapid laboratory diagnosis. A small skin biopsy specimen of the pink macule is placed in saline and examined by immunofluorescence with high-titred antiserum. A positive diagnosis can be made within four hours and specific antibiotic treatment started without delay. Unfortunately a few cases follow an atypical pattern $^{4}$ and the disease may not be suspected soon enough for even this test to be useful.

\footnotetext{
1 Woodward, T E, and Jackson, E B, in Viral and Rickettsial Infections of Man, eds F L Horsfall and I Tamm, p 1095. London, Pitman Medical, 1965.

2 World Health Organisation, Weekly Epidemiological Record, 1978, 53, 138

${ }^{3}$ Burgdorfer, W, Fournal of Medical Entomology, 1975, 12, 269.

${ }^{4}$ Medearis, D N, and Gang, D L, New England Fournal of Medicine, 1978, 298, 1071.

5 Woodward, T E, in An International Colloquium on Ebola Virus Infection and Other Haemorrhagic Fevers, ed S Pattyn. Prince Leopold Institute of Tropical Medicine, Antwerp, 6-8 December 1977.
} 